International Journal of English Literature and Social Sciences
Vol-6, Issue-1; Jan-Feb, 2021

\title{
The Educational Function of Chinese Folk Arts Exemplified by Shanxi Folk Kang Wei Paintings
}

\author{
Ji Lingzhu*, Chang Xiaojun
}

\author{
Taiyuan Normal University, City of Jinzhong, 030619, Shanxi, P. R. China \\ *Corresponding Author
}

Received: 29 Oct 2020; Received in revised form: 04 Jan 2021; Accepted: 20 Jan 2021; Available online: 29 Jan 2021

(C2021 The Author(s). Published by Infogain Publication. This is an open access article under the CC BY license

(https://creativecommons.org/licenses/by/4.0/).

\begin{abstract}
Like other forms of art, the functions of Chinese folk arts fall into three categories: physical, social and personal. The physical function refers to the practical applications of folk arts in everyday life and productive activities, whereas the educational function operates in the social and personal categories. Shanxi folk Kang Wei painting, nurtured by the profound Yellow River Civilization, has been explored as an example in our research. The field investigation and document studies show that the paintings are mainly intended for the edification of the masses from the social and personal perspectives: informing the masses of the important events, conducting aesthetic and moral education, passing on Confucius personal virtues, maintaining family values, strengthening national spirit, regulating and guiding folk customs, although the physical function of the paintings is to keep the beddings clean from wall dust.
\end{abstract}

Keywords-Chinese folk arts, Shanxi Folk Kang Wei painting, educational function, aesthetic edification, moral education.

\section{INTRODUCTION}

Created by Chinese people alongside the invention of tools, shelter and other basic appliances necessary in daily life, the social function of Chinese folk arts makes them arts of necessity, since they are used in everyday life, production, rites and ceremonies etc, to beautify people's life, enlighten them about Confucius ideas, improve people's personal behavior and even help them to master productive skills. As visual arts from ordinary people to meet common social needs, they present themselves among the popular masses in the forms of poetry, music, theater, dance, architecture and fine and applied arts. Chinese folk arts have written a magnificent chapter in human artistic history with their unique national style, various artistic forms of expression and tenacious artistic pursuit.

Shanxi, situated on the Loess Plateau in Yellow River Basin, has a five -millennium history of civilization with a rich and profound cultural heritage. It is well-known as a field of folk arts. Kang Wei painting, a kind of ancient folk interior decoration, was added in the list of Chinese National Intangible Cultural Heritage in the year 
2008. As indicated by the name, they have been painted around the surrounding walls of Kang (炕 ${ }^{[1]}$ as a physical protection for the beddings from the wall dust, and later as a kind of interior decoration. The regional form of folk art is colorful and diversified in subject matter and artistic features. People can read Chinese Confucius Culture, Taoist legends, stories from famous Chinese novels, classical dramas and people's folk activities etc in the paintings. Although the artistic techniques directly evolved from frescoes, the art form is a complex of murals, Chinese woodblock New Year prints, Chinese freehand and precise style painting, oil painting and colored architectural paintings. ${ }^{[2]} \&[3]$ The paintings can also be found in other provinces in the Yellow River Valley on the Loess Plateau such as Shaanxi, Hebei, Inner Mongolia and Gansu etc, where people have slept on Kang. Kang ( still used in some remote rural areas for heating in winter) has provided physical carrier and space for the art form. It is connected with the cooking stove both on the surface and beneath. The heat from the cooking fire in the stove transfers to the Kang from the reserved channels beneath, then it becomes a warm place for the family, similar to the fireplace in the sitting room in the West. The westerners sit on sofa or in armchair near the fireplace whereas the Chinese rural people in the north sit on the warm Kang. Therefore the room with Kang has four roles: bedroom, sitting room, kitchen and diningroom with the purpose of saving firewood in winter.

Besides Kang, the carrier, there are other prerequisites for better quality works of Kang Wei paintings in Shanxi area. In the ancient history of Shanxi, due to its special geographical location, Taoism, Confucianism and Buddhism, either local religions or the imported, all flourished, and temples had been built everywhere. Fresco painting techniques developed quickly. Shanxi had been a melting pot of different nationalities in Chinese history, and people of various origins brought their living habits and room decoration customs to this area. The religious atmosphere and the social environment of Shanxi in history prepared fertile cultural and artistic soil for the birth and prosperity of this art form. The local artisans moved the colorful paintings to people's homes after reforming the composition of murals in the temples and their religious themes. After years of inheritance and development, the social and personal functions of this art form far exceeds its physical function of keeping the beddings clean, since people (both the painters and the home owners) choose the patterns, colors and themes for spiritual and psychological demands instead of just protecting the beddings.

\section{AN IMPORTANT MEDIUM OF COMMUNICATION IN AGRICULTURAL SOCIETY}

The existing archeological evidence proves that the starting of Kang Wei paintings can be traced at least to the Song Dynasty ${ }^{[4]}$. For about one thousand years from the Song Dynasty until the Ming and Qing Dynasties, the Chinese production mode, political system and the ways of cultural transmission of the agrarian civilization remained nearly the same. The centralized feudal monarchy and self-sufficient natural economy had always been the fixed social political system and economic foundation. After the Revolution of 1911, although the social and political system changed, agriculture had remained the pillar of China's economy until the end of the $20^{\text {th }}$ century. TV sets only appeared in the homes of a few families in rural areas in the1980s. For so many years, Kang Wei paintings highlighted the role of mass media just next to the Chinese New Year woodblock prints in Shanxi area. The New Year woodblock prints were usually posted on the walls before the Chinese Lunar New Year or other important festivals. Before the thirties of the $20^{\text {th }}$ century literacy movement, most of the farmers were illiterate, so it was impossible for them to read books and newspapers. However, pictures of Kang Wei paintings and New Year prints could reach a broader audience, providing the local people an opportunity to inherit traditional culture and get to know the new happenings from the outside world.

The instilling power of Kang Wei paintings was even stronger than paper prints since New Year prints would be changed or removed whereas the Kang Wei paintings were painted on the walls surrounding the sleeping platforms and the family members could look at them several times every day. The home-owners paid the painters once to paint, and the paintings could be kept on the walls for many years if carefully preserved and looked 
after.

\section{THE TRANS-ERA EXPRESSIVE POWER}

The long-term educational function is endowed by its forceful trans-era expressive power, which is decided by the unique composition of Kang Wei paintings: the boundary pattern, Huakong ( the space for the major pattern) and screens (in some parts of Shanxi).The boundary patterns pass auspicious messages from ancient times, and content in Huakong and screens are the concentrated expression of people's good wishes and beautiful dreams or new happenings.

Boundary patterns are comparatively fixed with traditional Chinese patterns handed down for many generations, and they are the abstract representations of the real external world, containing the cultural codes.
Some of them were transplanted or evolved from the patterns in the temples or palaces, such as Kui Long ${ }^{{ }_{5} 1}$ or continuous Wan patterns ${ }^{\mathbf{1} 6 \mathbf{1}}$. The commonly used longevity pattern was borrowed from tombstone carvings. To the ancient Chinese, death meant eternal life in another world. The burial rooms of the rich and powerful ancient Chinese people were luxuriously decorated, as if they were still living a wealthy life underground. The pattern of Implied Eight Immortals of Taoism contains their magic weapons, referring to these immortals (暗八仙) and with the implicature of Chinese lucky number "eight". Other patterns are either the continuous use of one auspicious pattern or the combination of different kinds of auspicious patterns.

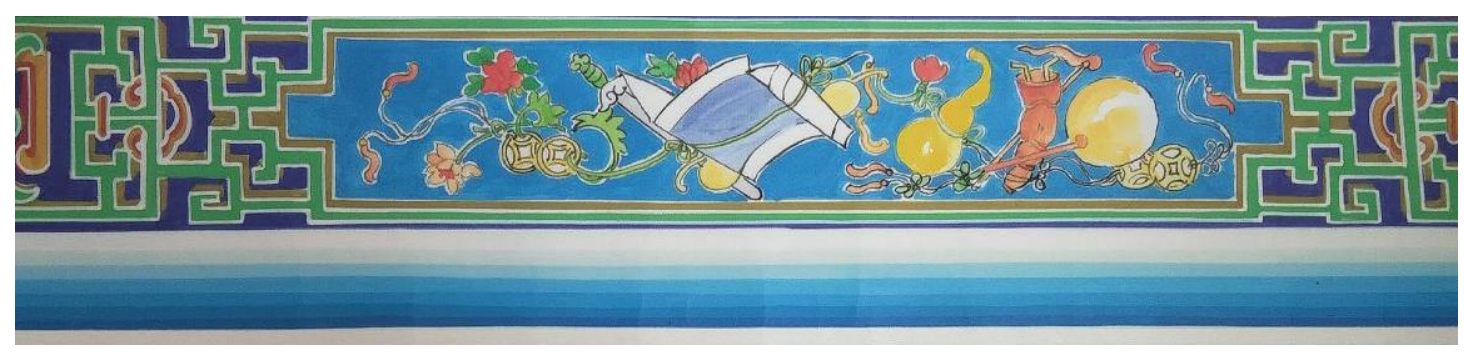

Picture 1. The Eight Immortals' Magic Weapons

Taken by the author On July 29,2020 in Yuanping Kangwei Paintings Cultural Company

The trans-era characteristics of this art form is mainly reflected in the pictures in the Huakongs and screens, the space for main-theme picture/pictures. There can be one or more Huakongs in a set of paintings. The number of the Huakong is decided by the theme of home-owners' choice. Pictures in Huakong and screen are usually the specific plots in traditional drama, scenes of real life events and visual descriptions of the beautiful sceneries such as mountains, flowers and rivers etc. The content in Huakong is characterized by features of the time. From the existing works, we can find stories from the famous dramas, well-known historical figures, Dr. Sun Yat-sen's famous words, the productive scenes in rural area shortly after the founding of the People's Republic of China. The paintings present a miniature of the social and political happenings, and they mirror the local people's aesthetic judgement and the development of their regional folk culture.

A general survey of the modern time themes of Kang Wei paintings will present us with the social, historical and cultural changes. The themes of most of the existing works painted before 1949 were the traditional, such as stories of filial piety and drama. A special one, found in an old house of Xiangyuan County, is a piece of calligraphy work with Dr. Sun Yat-sen's well-known words. According to some elderly villagers there, the home owner had been a well-educated rich businessman whose son had studied in the US in the early twentieth century and been a follower of Dr. Sun. ${ }^{{ }^{71}} \quad$ After the founding 
of The People's Republic of China, the themes of the paintings changed much faster than before, reflecting a clear and strong sense of class and the times. Painting themes of farming, factory work and the building achievements of New China etc replaced some of the traditional filial piety and auspicious content, such as Nanjing Yangtze River bridge, Young Shepherd Couple, Big Harvest, Beijing Railway Station etc. During

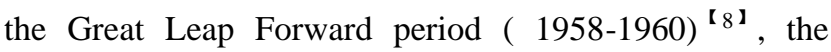
pictures such as Carp Jumping over the Dragon Gate ${ }^{\mathbf{I}_{9} \mathbf{1}}$, rockets, planes ,trains, cars, and even big corns and granaries were painted on the bedside walls. During the Cultural Revolution years ( 1966-1976), paintings of
Chairman Mao Zedong in army uniform as well as farmers and workers were popular. After 1978, the economic reform and opening to the outside world period under the leadership of Mr.Deng Xiaoping, the themes and images in the paintings became even more diversified, reflecting new changes in people's lives. In a recently completed work, Chairman Xi Jinping is visiting the farmers in a small village in Xingxian County, an old revolutionary base aerea in Shanxi, shaking hands and talking with them with an amiable smile on his face. The painting was completed shortly after President Xi Jinping inspected Xingxian, one of the old revolutionary bases, in June, 2017. ((Picture 2)

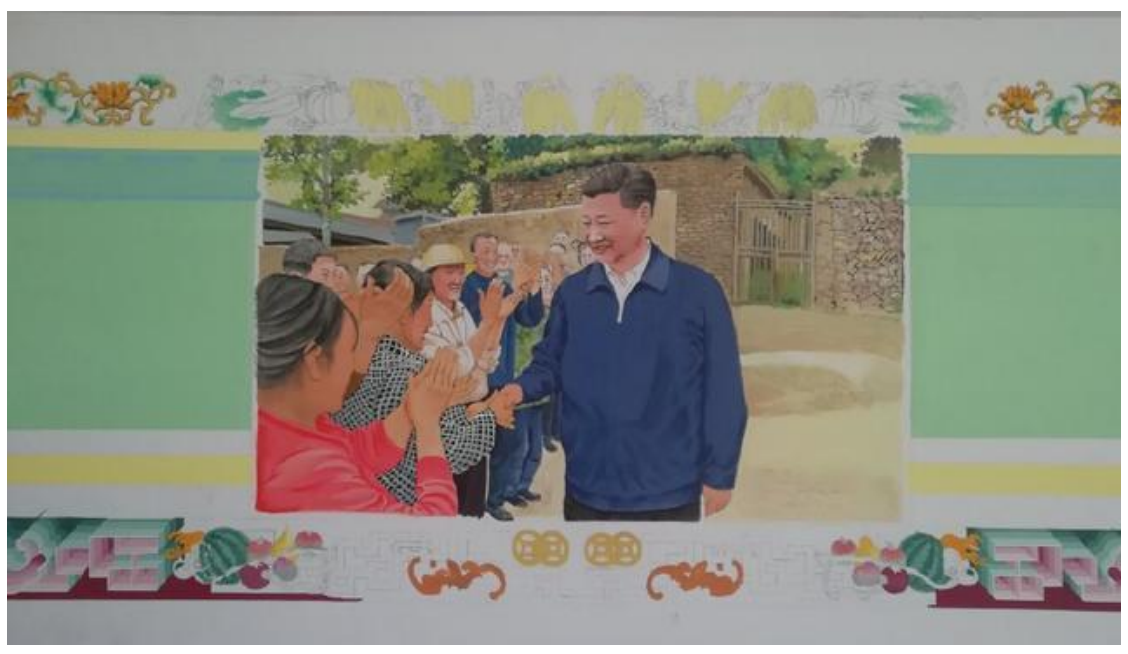

Picture 2 New Kang Wei painting: President Xi Jinping and the Villagers courtesy of 360 Pictures $^{[10]}$

During the years when transportation and communications were underdeveloped, those special pictures vividly reproduced the social and historical happenings in their limited small size, and left deep impression on the audience. From1949 to1990, many paintings had themes of political, economic and cultural changes, which assisted and consolidated the local people's understanding of the government's policies. To the local people at that time they were windows for them to know the new information of socialist development, and hence exerted an imperceptible influence on family members' ideology from 1949 to the 1990 's ${ }^{\text {[11 }}$.

\section{FUNCTION OF EDIFICTION AND EDUCATION}

\subsection{Human beings' primitive demands for} edification and education

The educational function of art has been an ancient proposition. Throughout different periods in Chinese history, a variety of art forms had possessed major status in their role of social education. During the Pre-Qin period (before $221 \mathrm{BC}$ ), music had been the most powerful. From the Han to the Song dynasties( 206BC--581AD), fine arts undertook more functions of enlightenment. Whereas in the dynasties of Yuan, Ming and Qing (1279--1911AD), operas and other performing art forms were the main ways for the 
general public to acquire moral edification. ${ }^{\mathbf{I}_{12} \mathbf{I}}$ Education aims at helping people to learn and emulate through creating positive and negative characters, while edification is intended for influence by osmosis.

Here is a quotation from The Analects of Confucius: "At the end of spring, when the making of spring clothes has been completed, to go with five or six newly capped youth and six or seven uncapped boys, perform the lustration in the river $Y i$, take the air at the Rain Dance altars, and then go home singing. " ${ }^{\mathbf{I}_{13} \mathbf{1}}$ In this paragraph, there is no moralizing, neither is there any typical characterization, but the harmonious sight presented by a couple of words has fascinated the readers. The early scholars over-emphasized the power of direct education, neglecting the instilling function of art works. Although it is difficult for us to give a dividing line between the functions of education and edification, a difference does exist. Education is rational, emphasizing the distinction between the right and wrong. Osmosis focuses on perception, guiding people's attitudes for life. Different themes of Kang Wei paintings combine education and edification together. This is similar to Confucius edification mechanism: moral education is the combination of direct teaching (from political system) and subtle influence (from folk customs), in other words a combination of political system and folk customs. Political system is a subjective consciousness while the folk customs are congenital. However in reality, they were often combined together. The theoretical basis and implementation path design of Confucian edification mobilize and integrate various social and cultural resources, subtly enlightening people in their daily lives. ${ }^{\mathbf{I} 14 \mathbf{I}}$

Aesthetic activities are the spiritual exchange and communication between man and his surrounding world, in which the subject and the object interact with each other in the most self-dependable way. They are the specific forms through which the subject can actively perform its own essential power, and the object can vividly present itself as it is. The evolution and flourishment of folk art reflects that human beings turned to spiritual pursuit from the primal stimulus of the objective material world, and they developed their perceptual experiences of the

ISSN: 2456-7620 objective world into beautiful and colorful Kang Wei paintings. The primitive spiritual demand is satisfied psychologically in the multi-functioned room decorated with the paintings. In years of productive activities, human beings' continuous accumulation of perceptual experiences promoted the maturity of this art form in Shanxi, the specific environment. The local people's cognitive ability and knowledge structure get improved constantly in the aesthetic activity. Since the local people and generations of painters have been immersed in the temple fresco surrounding for many years, it was very natural for them to turn to the art form for their psychological and spiritual demands and expressions.

In history, Shanxi had been the border between Han culture and nomadic ones. It had been ruled by the nomadic rulers for a long time(Sixteen States set up by five nomadic tribes from 304 to 589AD, and witnessed the great national amalgamations in Chinese history for several times. To rule the majority Han people effectively, these rulers kept learning the Han's indigenous Confucianism and Taoism, and at the same time vigorously promoted and supported the development of Buddhist religion and culture. This provided favorable conditions ( both socially and politically) for the flourishment and development of different religions in Shanxi: temples ( Buddhist as well as Taoist) were built everywhere, and Buddhist scriptures were copied and studied. Inside the temples, frescoes were painted on the walls. Until now, there still exists more than 230,000,000 square meters of ancient frescoes. That accounts for $70 \%$ of China's total. The murals before Yuan dynasty(1271--1368AD) make up even $90 \%$ of all the national remains. The theme of the murals covers religious content such as Confucianism, Taoism and Buddhism, as well as the local culture and customs. The paintings present the modern people with the exquisite skills of the painters of different dynasties, since they combine the local historical culture with the natural ecology in a vivid miniature of people's lives in ancient times. Based on the remains of the murals today, we can infer that the murals must have been much more magnificent during their own times than they are now, those painters must have mastered outstanding painting skills, and the wall construction techniques must have been highly developed since the walls in the temples are still 
standing after more than one thousand years .

The development of culture created new demands for an edification vehicle, which in turn enriched and diversified the local culture. The rise and flourishment of Kang Wei paintings made good use of the local conditions so that the enlightenment grew to be a good match to the local culture development. 76-year-old Mr. Gong Jinshou, who is still working for Yuanping Kang Wei Painting Company, says the most precious heritage the local people had inherited from local culture is Kang Wei painting. ${ }^{\mathbf{I}} 15 \mathbf{I}$

\subsection{Edification in daily life, and the life of edification}

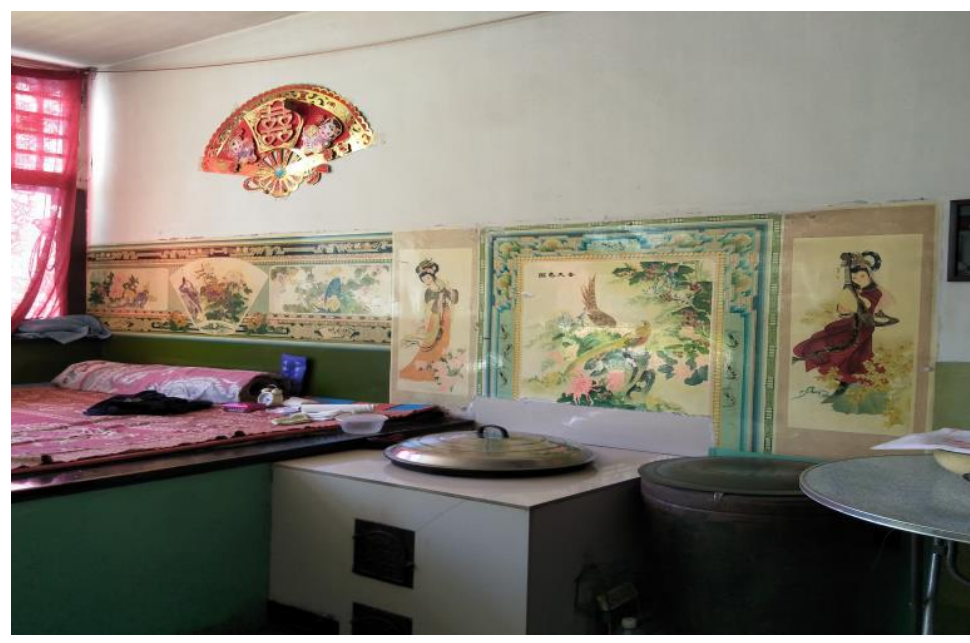

Picture 3. Kang Wei Painting in the bedroom with the cooking stove

Taken by Prof. Chang Xiaojun on Oct. 3, 2018 in Shenshan village, Yuanping County

Kang Wei paintings have provided the local people with handy teaching materials, easy to understand visual images and timely review and consolidations because they have been in the rooms serving four roles: bedroom, sitting room, kitchen and dining room. The edification function of the painting has permeated in people's daily lives, and their lives have become a process of edification, since for the local residents the first thing they have seen in the morning when opening their eyes is the painting, and so is the last thing they see every night before they go to sleep.

The homeowners in past years asked painters to paint opera characters, flowers and plants loved by the local people Although farmers had not received too much formal education, they knew the role of edification and osmosis of the everyday environment for their descendants, never allowing unhealthy and vulgar pictures to be painted on their walls. In days when illiteracy rates were high, painters were regarded as well-educated intellectuals because they were able to read, write, and paint and they knew many stories in the paintings. The homeowners usually discussed very carefully with the painters what to paint on their walls, exchanging their requests and suggestions in many turns before the final decision. A set of Kang Wei paintings was usually completed in five to seven days depending on number of Huakongs, the sophistication of the themes and the intricacy of the workmanship. During this period, the home owners treated the artisans to three meals a day, usually better quality than their own food. ${ }^{\mathbf{I} 16 \mathbf{I}}$

The local children grew up with the company of Kang Wei paintings which showed their journey from a new-born to an adult. When interviewed, 80-year old Mr. Liu Shaowei gave us a recount with strong nostalgic feelings, "I grew up looking at paintings on the surrounding walls of our big Kang. For as long as I could remember, our Kang Wei painting had been the play of The Romance of the Western Chamber. My mother cleaned it carefully with a big piece of wet cloth very often, so the paintings were largely intact when I went back to our old house about ten years ago, with only a few wall peelings. Although I had not read the book when I was a kid, I 
knew the story in it from looking at the eight pictures everyday and listening to the adults' chitchatting. I could remember all the beautiful buildings and sceneries in the pictures as well as the characters: Hongniang (the match-maker), Yingying (the wealthy young lady), and Zhang Sheng (the poor young scholar). To my parents' surprise, I could repeat the words and dialogues that matched each picture even before I learned to read”. ${ }^{\mathbf{I} 17}$

The paintings were an everyday leisure source for the adults and teaching materials for the children. In the old days, people usually gathered together every day to tell stories and jokes when they finished their farm work partly because of the lack of other forms of entertainments. In winter, there was not much farming work in the field, they would go to different homes instead of gathering outdoors. This was where the power of Kang Wei paintings came into play. To save firewood or coal, only the room with the Kang was heated, so the hospitable villagers would invite their visitors and guests to sit on the warm kang as a sofa to spend the long winter evenings together. The multi-functional warm room became their platform of information exchange and communication, and consequently the paintings on the walls became their topics for conversation. The home gathering was an evening salon in the neighborhood. Among a group of people, there was usually a raconteur, talkative and humorous. He/she would point to the paintings and told the others stories from the classical dramas or legends, making use of an ancient story to comment on a new event, evaluating the characters in the paintings, or spicing up a story with anecdotes from famous people. Scenery paintings with beautiful mountains, rivers ,a blue sky, and colorful flowers guided local people who had seldom been to the outside world to enjoy the landscape with their praising and yearning. "An uncle, one of my neighbors, knew a lot of stories. He told me many stories about Lord Guan and the national hero Yue Fei. He repeated the stories so many times that I could remember every detail, but I still enjoyed listening, and I often corrected him when he forgot the names of their weapons." 【18 1

At dinner time or before the children's bedtime, adults (parents, grandparents or uncles and aunts) would tell the kids the stories of characters in the pictures, expecting them to become as talented, virtuous and dutiful as the painted gentlemen, and as brave and righteous as the national heroes. The warm kang has always been a paradise for the young children during cold winters in rural areas, since the bright colors and different kinds of patterns were in line with the aesthetic needs of the babies, toddlers and young children. When they cried or felt bored, their parents or grandparents would point to the paintings on the bedside walls and babble with them. The childlike and playful instilling is just the actual performance of the edification function of this folk $\operatorname{art.}^{[19]}$

On special occasions, such as people moved into new houses, weddings, babies' birthdays, seniors' birthdays, or during Spring Festival and other important festivals, friends, neighbors and relatives gathered in the house for a celebration. The first things to catch people's sight were usually the colorful paintings on the walls. They would talk about the stories and figures, comment on the workmanship, and highly praise the home-owner's choice of themes, patterns and colors.

\subsection{Aesthetic Education}

From the wall protection to a window displaying culture and education, Kang Wei painting is the advance of human survival experience as well as the progress of human civilization. From the landscape paintings, the audience can appreciate the towering peaks in the high mountains, different shapes of flying waterfalls and flowing fountains, green hills and clear water, trees of all shapes and sizes etc. Besides, the painters usually add some verses or inscriptions after completing the pictures in beautiful calligraphy. The content of the verses and inscriptions match the pictures perfectly. They made the work enjoyable in three ways: as a painting, as a literary work, and as calligraphic achievement. ${ }^{[20]}$ The scenery paintings guide the local people to scenic spots and historical sites in different places, such as Summer Palace and Beihai White Pagoda in Beijing, the West lake in Hangzhou, the famous gardens in Suzhou, Yangpu Bridge in Shanghai and the skyscrapers in Shenzhen etc.

The still life paintings are usually on the walls above 
the bellow and the stove, where the Chinese Kitchen God is enshrined. Therefore, the cooking pot wall painting has been regarded the most important by both the painters and the house owners. The content in the cooking pot wall painting is designed for the Kitchen God as offerings. According to Chinese folk religion, every year, on the $23^{\text {rd }}$ of December in the Chinese Lunar Calendar, the Kitchen God goes to heaven to see the Jade Emperor, the ruler of the Heavens, to report on the conduct of the families. Therefore people hope the Kitchen God can report their good conducts to the Jade Emperor, and bring back his blessings for the whole family. So watermelons, moon-cakes, sweets and other fruits are often painted on the cooking pot wall. After the founding of People's Republic of China, Chairman Mao Zedong's image and his slogans were painted on the cooking pot wall, since the people of China regarded Chairman Mao as their savior because the government under his leadership redistributed the land, houses and other property, and treated poor people as equals.

The folk artisans of many generations combined a variety of expressive techniques after years' of development: Chinese painting skills, such as painting with exact delineation and enriched colors, impressionistic ink painting, and New Year woodblock prints etc. Later, the younger generation of painters borrowed techniques from the calendar poster paintings, decorative powder paintings and the western realistic oil paintings. The comprehensive use of different kinds of art forms helps to widen the audience's scope of appreciation, and pave a way for the formation of potential aesthetic skills, aesthetic sensibility and aesthetic creation. "My father has been a Kang Wei painter for many years. When I was a little boy, I often watched him painting and helped him with tools and pigment boxes. My own understanding and interest for painting came directly from Kang Wei painting in my home. The theme and art form introduced me to an unlimited imagination space, and aroused my strong desire to explore the unknown. The interactive communication between presentation and reception will inevitably result in a deep-rooted mental structure for the long term audience " [21]. Whatever freedom the audience enjoys in appreciation, he/she is bounded to be regulated and affected by the art form once the aesthetic object for appreciation is chosen.

After absorbing numerous adornment art forms, the boundary pattern of Kang Wei Paintings has evolved into a comprehensive body of artistic expression, a real pluralistic co-existence. The artistic volition of a nation gets the purest expression in adornment art. ${ }^{[22]}$ In the development process of different periods, climes and nations, the local people have created a common art form: the decorative art, a visual form that reflects regional uniqueness and inherent artistic sense. The boundary patterns of the paintings, the abstractions of the objective world, provide a special perspective for the audience to understand and appreciate art, and upgrade their interpretation of the objective world in the regional environment to a high level sublimation. Under the circumstances, the audience's knowledge of natural phenomena will no longer stay on the level of objective existence, but move forward to a long-standing subtle influence.

\subsection{Moral Education}

Kang Wei paintings cover a wide range of subjects, including stories and figures in the Chinese idioms and historical anecdotes, such as Mencius Mother Moving Three Times to Find Good Neighbors for the Sake of Her Son's Education, Kong Rong Sharing the Pear and The Drunk Poet Li Bai etc; complete stories from the classical Chinese novels and dramas, such as the Romance of the Western Chamber, the Romance of the Three Kingdoms, Water Margin, and Madam White Snake, etc. These interesting historical stories pass Chinese social values, historical knowledge and Confucius moral ideas to the people via instilling and osmosis.

The local people and painters divide Kang Wei paintings into the following categories:

\section{Character series}

- Love stories, Miss Yingying Listening to Guqin, Butterfly Lovers etc.

- Edification and Education series: Stories of Twenty-Four Filial Deeds, Yue Fei' s Mother Tattooed His Back with Four Chinese Characters "Serving the Country 
with Supreme Loyalty", $S u$ Wu, the Shepherd, and Si Maguang Broke the Cylinder etc.

- Fairy tales: Chang Er Flying to the Moon, Magu's Birthday Offerings etc.

- Historical events: Peach Garden Sworn Brothers, Liu Bei Paying Many Visits to Zhu Geliang's Cottage etc.

\section{Flowers and birds}

Flower and bird paintings are very popular with the local people as they are beautiful and bear good symbolic meanings.

- Plants: Peony symbolizes nobility. Chrysanthemum stands for seclusion. Lotus refers to the moral quality of rising unsullied from the mud. Bamboo branches imply noble characteristics. marriage. The cuckoo crying blood tells people the sorrow of losing one's homeland. The lamb kneeling down to suckle and the young crow feeding its parents instill the idea of filial piety. The picture of a golden pheasant and a flower means "icing on the cake". The combination of cat, butterfly and peony means riches and honor. If a crane goes together with a deer in the painting, it is hoped that spring is everywhere in the country, and everything is full of vitality. People's yearning for riches, peace and honor is pinned with the picture of peony and peacock. etc. ${ }^{[23]}$

The stories, characters, flowers and birds in these allegorical paintings have brought the people in the rooms aesthetic enjoyment and moral osmosis.

- Animals: The dragon is the emperor. The kylin is the saint. The turtle signifies longevity. Harmonious chirping of two mythical birds means a happy

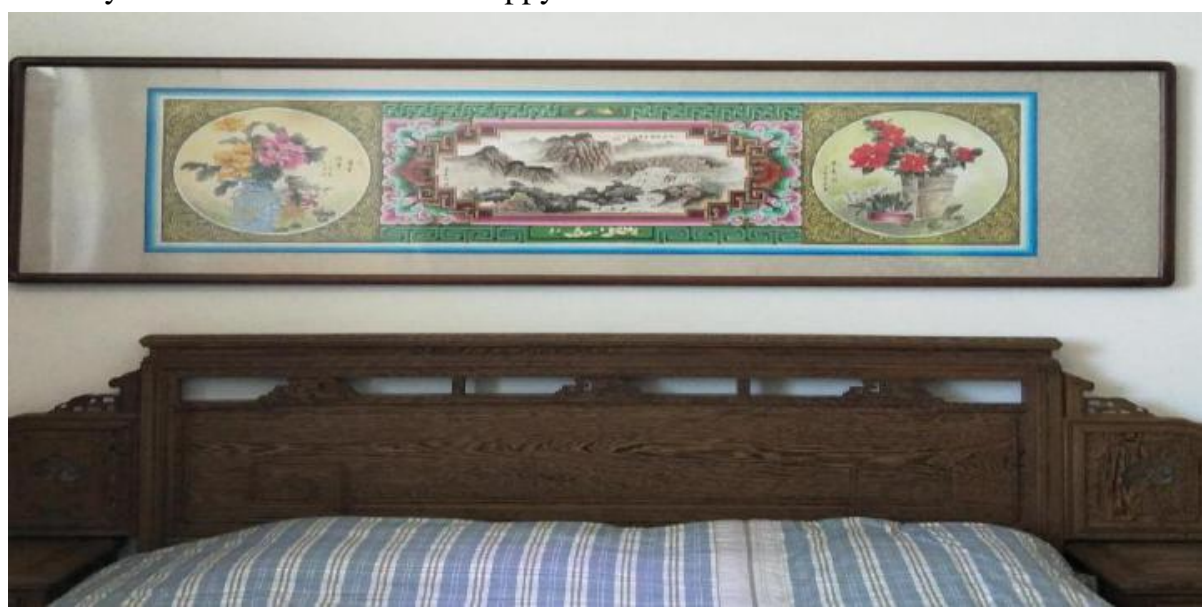

Picture 3. Taken by Liu Yanyan (the author's student) on August 9, 2020 in Yuanping County

\subsubsection{Passing Confucius Personal Virtues}

In connection with humanity, Confucius proposed many virtues, such as rightness, propriety, wisdom, trustworthiness, loyalty, reciprocity, filial piety and brotherly love etc. To Confucius, a man who had virtues was a gentleman. A virtuous man is always open and sincere, free from worries and fears, at peace with himself, the people around him and the world. The moral standards and ethical principles for the overall quality of gentlemen in traditional Chinese culture have remained to be the themes of Kang Wei paintings for generations. These philosophical ideas were too difficult for the illiterate common Chinese people. However, the paintings on the bedroom walls explained the profound ideas in a simple and understandable form. These virtues have been the core of the ancient Chinese value system, and the standard by which people tell the good from the evil.

\subsubsection{Promoting and Maintaining Family Values.}


In traditional Chinese culture, the position of family is paramount. Confucianism emphasizes the qualities of a gentleman: perfecting self morals, running a model family, managing a successful vassal state, and finally achieving the supreme goal that all people would expect: enjoying a peaceful life and never being exposed to any wars. Family is in the core position. Kang Wei paintings have spared no efforts to advocate and maintain Chinese family values, and given prominence to filial piety. The themes of affectionate father and dutiful son, providing for the elderly, and harmonious family have taken up a big proportion in the paintings before 1949 for nearly a thousand years, such as The Stories of Twenty-Four Filial Deeds, Kong Tong Giving the Bigger Pear to His Brother.

Another important subject is complimenting harmonious relationship between husband and wife and fun in family life, such as Butterfly Lovers, A Dream of the Red Mansion, Angel and Cowboy Marriage, and Marriage Gods. These works represent people's good wishes for happy and harmonious family life and pursuit for true love.

All the family paintings transmit Chinese traditional family ethical conceptions: respect for seniority, being tolerant and generous with each other, and pursuit for harmony, happiness and health, etc. These ideas gradually root in the hearts of every social member, internalize into people's psychological consciousness, and finally, guide people's daily behavior subtly.

\subsubsection{Interpreting and Strengthening the National Concept}

One of the eternal themes of Kang Wei paintings is promoting profound national consciousness, often reflected in the pictures of historical events and Chinese traditional dramas. The well-known paintings of Yang Family Generals and General Yue Fei's Army eulogize national heroes who bravely resisted the foreign invaders.

The themes for the same national heroes keep reforming with the change and development of the times. Lord Guan Yu is a good example. He was a real person, a native of Shanxi, and one of Liu Bei's sworn brothers and loyal generals in the Three Kingdoms' Period(220-280AD). He had always been regarded as the Saint of War whose duty was to ward off the evils and attack against the sinister enemies in the historical period when military conflicts among different kingdoms frequently occurred, and ordinary people were in need of protection from powerful figures. Starting from the Qing Dynasty(1616-1911AD), Guan Yu has been worshipped as Military God of Wealth. Commerce developed and prospered quickly and there were more and more businessmen, who worried about the risks in their business and hoped that the God of War could grant them his divine protection. Therefore the God of War took up a part-time job---being the Military God of Wealth. After the reforming and opening to the outside world( starting from 1978), the Chinese economy further developed and commercial activities became wide-spread and more frequent, and the God of Wealth turned into Guanyu's main job. His image as the Wealth God appeared everywhere in the restaurants, hotels and other business places as well as people's homes in the forms of clay and dough figurines, images in the wall paintings etc. The seemingly reasonable result is that quite a number of young people who are not very familiar with Chinese ancient history only know Guanyu as the God of Wealth. $\mathrm{He}$ is a successfully deified national hero no matter what kind of roles he has been given by the ordinary Chinese people. Deification of a real person who is well-respected has been one of the motives of traditional Chinese culture.

Besides the traditional themes, the subject matter of Kang Wei paintings not only advances with the times, but constantly pioneers and innovates during 1960s-70s because of the radical changes. There appeared many works praising the Communist Party, our great leaders, the new achievements of the socialist construction, which is the inheritance and sublimation of national consciousness and patriotic feelings.

\subsubsection{Regulating and Guiding Folk Customs}

The images and pictures in the paintings not only determine the nature of folk activities, but also regulate the form and content of them to some extent. The comprehensive design of Kang Wei painting gradually forms its own unique modeling method and structural style in the constraints of various collective consciousness activities, and also creates its own corresponding criterion 
of aesthetic judgement. With constant development, the common will of public aesthetic activities and unified spiritual structure have been built in the art form of Kang Wei paintings. Transmitting cultural information has become its dominant way of existence. The images of truth, goodness and beauty from the society and the natural world cling to the walls of the local people's rooms with Kang. Then, the audience acquire the information codes via its direct visual examples. Once the artists express their feelings with the help of the media, the fresh and unique mode of viewing the world will gradually become the popular way that will be accepted by more and more people, and will finally turn into the conventional pattern of thinking ${ }^{[24]}$. Kang Wei paintings contain folk cultural information for blessings, wealth, reproduction worship (more sons equals more happiness), well beings, auspiciousness and health. These symbolic elements are the fundamental philosophical concepts, which regulate people's behavior and aesthetic psychology.

Due to people's pursuits for auspiciousness, riches and honor, Kang Wei paintings became the most appropriate means to decorate folk festivals. For many years, when people in Shanxi built new houses or prepared the wedding room for their sons, they would spend a lot of money to invite well-known painters to complete a set of exquisite bedside wall paintings to beautify the home environment, but more importantly to ward off evil spirits and bring about good luck for the new family. In wedding houses, the background color is usually the traditional lucky red, and the commonly found images were a young boy and a young girl holding a peach and a pomegranate in their hands respectively: a cat catching butterflies, lotuses and lilies; two mandarin ducks tumbling merrily in the water; twin lotus flowers on one stalk; etc. The implications of these images are all about good wishes for the new couple to have more sons, more happiness, and affectionate love for each other. A local saying has been very popular for many years in northern Shanxi. Rich villages invite actors and actresses to perform the traditional Chinese operas on festivals, and wealthy families have exquisite Kang Wei paintings. No matter how poor a man might be, and how simple his preparation for the wedding will be, he should at least have a set of
Kang Wei paintings ready for his bride before the wedding day. [25] The themes of wedding room Kang Wei paintings advanced with the times. After the reforming and opening to the outside world in the late 1970s, the economic conditions of the ordinary families improved a lot, and local people had better preparations for their weddings in the 1990s: usually new houses and electric household appliances, etc.

The Chinese New Year has always been the most important festival for Chinese people home and abroad. In Shanxi, the painters are very busy in winter. Before the Lunar New Year, the local artisans often work overtime to complete the new Kang Wei paintings and fix the broken ones for the home owners. The houses are carefully and thoroughly cleared and cleaned, esp. the paintings. Before the $23^{\text {rd }}$ of December in the Lunar Calendar, people prepare barley sugar candies ( usually in the shape of a small watermelon) and bake special cakes as farewell treat for the Kitchen God before he goes to Heaven for the annual report. Then people will prepare a big feast and light fireworks to welcome him back on the eve of Lunar New Year.

\section{CONCLUSION}

Starting from the physical function of preventing wall dust from polluting beddings and clothes, local interior decoration gradually has been endowed with more and more connotations of culture and missions of enlightening and educating the public. They have regulated and constrained the patterns of people's lives and production with an invisible power, and guided local people's behavior as an unconscious force. Sometimes the folk customs even work better than legal provisions in solving disputes among the rural people, and maintain the inheritance order of the agricultural civilization. With the gradual decline of impergium and the advent of modern civilization, the educational function of the folk paintings has been replaced gradually by various kinds of convenient and efficient modern mass media and education methods. It seems that we are doing archeological field work when discussing the edification and education function of Kang Wei paintings, losing the necessary practical significance. However, the folk art form itself and 
the traditional Chinese value and belief it carries have already become a good example for modern mass media and ideological and moral education. No matter in big cities or remote mountainous villages in China, picture posters of the core socialist values and traditional Chinese virtues are on the walls of the neighborhoods and bulletin boards in public places. It is very gratifying for us to see that the ancient folk art form and its social function have been inherited and developed dynamically. ${ }^{[26]}$

Similar to Kang Wei paintings, other traditional Chinese folk arts, such as paper-cuts, embroidered pieces, New Year woodblock prints etc, all had rich connotations of the main stream Confucian values and culture besides their physical functions in daily use in different historical periods. This characteristic has ensured and enabled the penetration and transformation of Confucian education in people's practice of everyday life. There has seemed to be an inherent self-organization in which the interaction between the political system and customs promote folk arts to complete the edification function for the general masses. The long standing traditional Chinese mechanism has functioned for thousands of years to civilize the masses. In different dynasties in Chinese history, there had been constant interactions between folk arts and official high arts. Usually it had been the high arts that exerted more powerful influence upon the folk arts with rulers' ideology and aesthetic tastes. Then the ruling class' ideology would reach the general masses in the folk artistic forms which were easy and approachable for the public after been artistically polished by the folk artisans.

In present China, to strengthen people's cultural awareness and re-build our cultural confidence, more and more folk art forms are used to spread governmental policies, public and cultural events with positive energy, social morals and regulating personal behavior. The educational and edifying system is now stereoscopic and all-round with folk arts, high arts and various kinds of official and social media.

\section{ACKNOWLEDGEMENTS}

1. This article is phased achievement of the following research projects
1.1 Inheritance and Publicity of Shanxi Folk Kangwei Painintgs (No.2019-10,Document of Taiyuan Normal university)

1.2. Key Project sponsored by China Social Science Funds: Genealogy of Folk Cultural Resources in Shanxi, Shaanxi and Henan Provinces and the Empirical studies of Its Innovative Development (No.19ZDA185)

1.3. Folk cultural resources in interpreting class supported by Taiyuan Normal University (No. JGLX 2041).

2. We are deeply indebted to the help of all the interviewees in our field investigations.

\section{REFERENCES}

[1] Kang (炕): the sleeping platform which can be heated in winter, made of adobes, the loess, and bricks, commonly used in the north of China, now mainly in the rural areas where there is no central heating system.

[2] Chang Xiaojun, On the Art Form and Educational Function of Yuan Ping Folk Kang Wei Paintings. Decoration. 2014. pp122-124.

[3] Hao Xiumei. The Artistic Features of Xiangyuan Kang Wei Paintings, Art Observatory, 2012, vol 7. p.70.

[4] Compiling Committee of Yuanping Country Records, Yuanping County Records. China Science and Technology Press, 1991. P 31

[5] Kui Long (喨龙) pattern: a single-foot dragon, representing nobleness, happiness and good luck. Its pattern often appeared on bronze wares in the Shang Dynasty and on china (瓷器) in Ming and Qing Dynasties. Now there are a lot of variations of Kui Long pattern in Chinese architecture, interior decoration, fashion design and wall paintings, etc.

[6] Continuous Wan Pattern: in Chinese Patterns, there are many variations of the Chinese character wan( 万), meaning eternity and forever. It is an auspicious pattern in Chinese traditional culture.

[7] Zhang Yuegong\& Zhang Ji, Kang Wei paintings. Beijing: The Commercial Press.2017. pp. 239-250.

[8] Political movement in China around 1958, boasting and exaggerating the economic development 
[9] A Chinese idiom, meaning if a carp tries hard to pass the Dragon Gate, it will become a dragon. It is often used to encourage people to work hard to improve their social status.

[10] http://image.so.com/i?src=360pic strong \& $\mathrm{z}=1 \& \mathrm{i}=0 \& \mathrm{cmg}=$ cd723879b2d95b9e416d2ca2aeeebb57\&q=\%E7\%82\%95\% E5\%9B\%B4\%E7\%94\%BB\%E5\%9B\%BE\%E7\%89\%87\#I last retrieved on December 15, 2019.

[11] Chang Xiaojun, On the Art Form and Educational Function of Yuan Ping Folk Kang Wei Paintings. Decoration. 2014. pp122-124.

[12] Li Xiangwen, The Contemporary Value of the Educational Function Reflected in Ancient Artistic Works, Chinese Social Sciences Weekly. December, 9, 2016.

[13] Confucius, The Analects, translated by Arthur Wayley, Beijing: Foreign Language Teaching and Research Press, 1998. p. 139.

[14] Yu Liang, Women's Needle Work and Edification: Research on the Confucian Edification mechanism reflected in Caozhou Braided Rope.[D] China Arts Research Academy, 2013.

[15] From the interview with Mr. Gong, Jinshou, 76 years old Kang Wei Painter in Yuanping County, interview by Gao Min, a student in my research group in Yuanping Kang Wei Painting Company face-to face on February 22, 2019.

[16] From the interview with Mr. Liu Shaowei

[17] From interview with Mr. Kang Jing,

[18] Yan Liangzhen, On Kang Wei Paintings in Northern Shanxi from the Perspective of Folklore[D]. 2012, Shanxi University.

[19] Ding Wangdao, A Glimps of Chinese Culture. Foreign language Teaching and Research Press. (in Chinese and English). 2001, p 73, \& p 78.

[20] Chang Xiaojun, Artistic Characteristics of Yuanping Kang Wei Painting, Taiyuan: Shanxi People's Publishing House, 2014. P 30-32.

[21] Schellekens, E. Aesthetics and Moral Education, translated by Wang Keping etc. Chengdu: Sichuan People's Publishing House. 2009. p.38.

[22] Summarized from the interviews with Mr. Hao Yanming, Mr. Zhang Yuegong, Ms. Zhang Huahua
[23] Arnheim Rudolf, Visual Thinking, translated by Teng Shouyao, Chengdu: Sichuan People's Publishing House, 2007, p.10.

[24] Summarized from the interview with Mrs Wang,

[25] Wilcox Emily E. Dynamic Inheritance: Representative works and the authoring of Tradition in Chinese Dance. Journal of Folklore Research, 2018, Vol.55, No.1. pp. 77-111.

\section{THE INTERVIEWEES WHO PARTICIPATED IN OUR FIELD INVESTIGATION}

1. Mr Kang Jing 72 years old, Kang Wei painter In Yuanping County, interviewed on July 28, 2018 in Yunaping by my student Liu Lifang.

2. Mr Hao Yanming, 76, Kang Wei painter in Xiangyuan County, Shanxi, interviewed by my students Liu Lifang and Li Rui on May 3, 2020.

3. Mr Liu Shaowei, 80 years old, a retired newspaper reporter, a native from Yuanping County, interviewed by the author in Taiyuan in July, 2019

4. Mrs Wang, an 85-year-old woman in a village of Xiangyuan County, one of my students' neighbors, interviewed by Miss Li Rui and Miss Liu Yanyan in my research group in July, 2018 at her home

5. Mr Zhang Yuegong, former Director of Xiangyuan County Cultural Centre, interviewed by the author on Feb. 12, 2020 on the phone.

6. Ms Zhang Huahua, 68, a housewife in Daixian County, interviewed at her home by Miss Song Jiaqi and Miss Rongji in my research group in July, 2019. 